\title{
Subclinical Epstein-Barr Virus Primary Infection and Lytic Reactivation Induce Thyrotropin Receptor Autoantibodies
}

\author{
Naohiro Tamoto,, Keiko Nagata,, Sayuri Hara, ${ }^{1}$ Yuji Nakayama, ${ }^{2}$ Satoshi Kuwamoto,, Michiko Matsushita, ${ }^{3}$ \\ Masako Kato, ${ }^{1}$ and Kazuhiko Hayashi ${ }^{1}$
}

\begin{abstract}
Epstein-Barr virus (EBV) is a herpes virus that mainly infects in B lymphocytes and occasionally reactivates lytically. Most individuals have been infected with EBV primarily in their childhood with no symptoms, and the virus persists latently for life. We have previously reported that EBV-infected B cells with thyrotropin receptor autoantibodies (TRAbs) on their surface $[\mathrm{TRAb}(+) \mathrm{EBV}(+)$ cells] were present in the peripheral blood mononuclear cells (PBMCs) of healthy adult controls and patients with Graves' disease, and that TRAbs released in the culture medium of PBMCs containing TRAb $(+) \mathrm{EBV}(+)$ cells by EBV reactivation. EBV lytic reactivation induced the differentiation of host $\mathrm{B}$ cells into plasma cells and antibody production. Various autoantibodies have been detected during the acute phase of infectious mononucleosis (IM) that is the symptomatic primary infection of EBV. Therefore, the autoantibody production may be induced by the asymptomatic primary infection. In this study, we examined the presence of TRAb $(+)$ cells, $\mathrm{EBV}(+)$ cells, and TRAb(+) $\mathrm{EBV}(+)$ cells in PBMCs from 29 healthy or subclinical children without Graves' disease and one cord blood that were divided into six age groups, and also measured plasma TRAb levels. The results obtained demonstrated that low levels of TRAb production occurred with EBV primary infection and lytic reactivation in children without symptoms of IM. Furthermore, the populations of TRAb(+) cells, EBV(+) cells, and TRAb(+) EBV(+) cells were small in the period of primary infection, but they potentially expand with repeated EBV lytic reactivation. This may partly explain why the onset of Graves' disease often occurs in young adults, but rarely in infancy.
\end{abstract}

Keywords: Epstein-Barr virus, viral reactivation, autoantibody, Graves' disease, thyrotropin receptor autoantibody (TRAb), asymptomatic infection

\section{Introduction}

$\mathbf{E}$ PSTEIN-BARR VIRUS (EBV) is a B lymphotropic herpes virus latently infected in most adults (7). EBV sometimes reactivates lytically and releases a large number of progeny viruses from host cells.

We previously reported the presence of EBV-infected B cells with thyrotropin receptor antibodies (TRAbs) on their surface $[\mathrm{TRAb}(+) \mathrm{EBV}(+)$ cells] in the peripheral blood of not only patients with Graves' disease, but also healthy volunteers (11).
TRAb is an autoantibody that causes Graves' disease, an autoimmune hyperthyroidism (8). TRAbs were secreted into the culture supernatant when the induction of EBV reactivation was applied to lymphocytes containing TRAb(+) EBV(+) cells (13).

Our findings suggest that EBV lytic reactivation promotes the differentiation of B cells into plasma cells and antibody production.

In primary EBV infection, some infected cells become lytic $(1,7)$. Various autoantibodies have been detected in the sera of some cases during the acute phase of infectious mononucleosis (IM): a symptomatic EBV primary infection

\footnotetext{
${ }^{1}$ Division of Molecular Pathology, Department of Pathology, Faculty of Medicine, Tottori University, Yonago, Japan.

${ }^{2}$ Division of Radioisotope Science, Research Initiative Center, Organization for Research Initiative and Promotion, Tottori University, Yonago, Japan.

${ }^{3}$ Department of Pathobiological Science and Technology, School of Health Science, Faculty of Medicine, Tottori University, Yonago, Japan.

(C) Naohiro Tamoto et al., 2019; Published by Mary Ann Liebert, Inc. This Open Access article is distributed under the terms of the Creative Commons Attribution Noncommercial License (http://creativecommons.org/licenses/by-nc/4.0/) which permits any noncommercial use, distribution, and reproduction in any medium, provided the original author(s) and the source are cited.
} 
$(7,14,16)$. These findings indicate that antibody production is induced by EBV primary infection and lytic infection.

If autoantibody production occurs in subclinical EBV infection, TRAb(+) EBV(+) cells or serum TRAb may be detected in healthy children at the age of EBV primary infection.

The aims of this study were to show TRAb production during EBV primary infection or lytic reactivation even if subjects were asymptomatic, and demonstrate the timedependent expansion of TRAb(+) cells, EBV $(+)$ cells, or $\mathrm{TRAb}(+) \mathrm{EBV}(+)$ cells in healthy Japanese children in six age groups, which may contribute to our understanding of why the onset of Graves' disease often occurs in young adults, but rarely in infancy.

\section{Materials and Methods}

\section{Subjects}

We collected peripheral blood from 29 children and one cord blood sample. Blood samples were classified into 6 age groups: 4 months or younger, 5-8 months, 9-12 months, 1-5 years, 6-10 years, and 10-15 years (Table 1). Cases 174 and 175 were twins, and their grandmother had thyroid disease.
We obtained assent from children and written informed permission from their parents. A pregnant woman provided informed consent for the collection of a cord blood sample. This study protocol was approved by the Medical Ethics Committee for Human Subject Research (No. 707) at the Faculty of Medicine, Tottori University, Yonago, Japan.

\section{PBMC preparation and culture}

PBMCs were separated using a Ficoll-Conray density gradient and stored at $-80^{\circ} \mathrm{C}$, whereas plasma samples were stored at $-20^{\circ} \mathrm{C}$ until used.

Before flow cytometry, PBMCs were cultured for 2 days in RPMI 1640/10\% fetal bovine serum with $0.1 \mu \mathrm{g} / \mathrm{mL}$ cyclosporine A, as described previously (11-13), to suppress T cell function and enrich the B cell population.

\section{Fluorescent staining of PBMCs}

According to our previous study (11), PBMCs were incubated with $0.025 \mu \mathrm{g} / 10^{6}$ cells of recombinant human thyrotropin receptor (TSHR) (Abnova, Taipei, Taiwan) at $4^{\circ} \mathrm{C}$ for $30 \mathrm{~min}$ and then washed. They were incubated with

Table 1. Profiles

\begin{tabular}{|c|c|c|c|c|}
\hline No. & Age & Male/Female & Blood collection & Family history and symptom \\
\hline \multicolumn{5}{|c|}{ Cord, $1-4 \mathrm{M}$} \\
\hline 169 & Cord & - & 2015.6 .26 & - \\
\hline 131 & $4 \mathrm{M}$ & Female & 2014.4.16 & Fever \\
\hline 152 & $3 \mathrm{M}$ & Male & 2014.9 .16 & - \\
\hline \multicolumn{5}{|l|}{$5-8 \mathrm{M}$} \\
\hline 126 & $8 \mathrm{M}$ & Female & 2014.4.16 & - \\
\hline 156 & $7 \mathrm{M}$ & Male & 2014.10 .21 & Fever \\
\hline 173 & $7 \mathrm{M}$ & Male & 2015.9 .8 & - \\
\hline 181 & $7 \mathrm{M}$ & Male & 2016.3 .9 & - \\
\hline 183 & $7 \mathrm{M}$ & Male & 2016.3 .15 & - \\
\hline \multicolumn{5}{|l|}{$9-12 \mathrm{M}$} \\
\hline 134 & $11 \mathrm{M}$ & Male & 2014.4 .30 & Fever \\
\hline 153 & $11 \mathrm{M}$ & Male & 2014.9.17 & - \\
\hline 179 & $10 \mathrm{M}$ & Male & 2016.2.12 & - \\
\hline 180 & $9 \mathrm{M}$ & Male & 2016.2 .12 & Fever \\
\hline 182 & $11 \mathrm{M}$ & Female & 2016.3 .15 & Fever \\
\hline \multicolumn{5}{|l|}{$1-5 \mathrm{Y}$} \\
\hline 127 & $4 \mathrm{Y} 10 \mathrm{M}$ & Male & 2014.4.16 & Fever, enlarged tonsils \\
\hline 128 & $1 \mathrm{Y} 7 \mathrm{M}$ & Female & 2014.4.16 & - \\
\hline 130 & $2 \mathrm{Y} 8 \mathrm{M}$ & Male & 2014.4.16 & Fever \\
\hline 132 & $1 \mathrm{Y} 1 \mathrm{M}$ & Female & 2014.4 .16 & Fever \\
\hline 142 & $2 \mathrm{Y} 5 \mathrm{M}$ & Male & 2014.5.20 & Enlarged tonsils \\
\hline 168 & $2 \mathrm{Y} 6 \mathrm{M}$ & Female & 2015.6 .2 & - \\
\hline \multicolumn{5}{|l|}{$5-10 \mathrm{Y}$} \\
\hline 129 & $5 \mathrm{Y} 1 \mathrm{M}$ & Female & 2014.4.16 & Swelling of the cervical lymph nodes \\
\hline 139 & $6 \mathrm{Y} 10 \mathrm{M}$ & Female & 2014.4 .30 & - \\
\hline 143 & $8 \mathrm{Y} 11 \mathrm{M}$ & Male & 2014.5.20 & Fever \\
\hline 149 & $9 \mathrm{Y} 4 \mathrm{M}$ & Male & 2014.7 .8 & Swelling of the cervical lymph nodes \\
\hline 171 & $5 \mathrm{Y} 8 \mathrm{M}$ & Female & 2015.7 .7 & Fever \\
\hline 172 & $9 \mathrm{Y} 1 \mathrm{M}$ & Male & 2015.7 .7 & - \\
\hline \multicolumn{5}{|l|}{$10 \mathrm{Y} \sim$} \\
\hline 174 & $14 \mathrm{Y}$ & Female & 2015.12 .24 & Maternal grandmother: Graves' disease \\
\hline 175 & $14 \mathrm{Y}$ & Female & 2015.12 .24 & Maternal grandmother: Graves' disease \\
\hline 176 & $13 \mathrm{Y}$ & Male & 2015.12 .24 & - \\
\hline 177 & $13 \mathrm{Y}$ & Male & 2016.1 .4 & - \\
\hline 178 & $12 \mathrm{Y}$ & Male & 2016.1 .4 & - \\
\hline
\end{tabular}

M, month; Y, year. 
$0.001 \mu \mathrm{g} / 10^{6}$ cells of biotinylated goat anti-TSHR immunoglobulin G (IgG) (Santa Cruz Biotechnology, Santa Cruz, CA) at $4^{\circ} \mathrm{C}$ for $30 \mathrm{~min}$ and then washed. PBMCs were subsequently incubated with $1 \mu \mathrm{g} / 10^{6}$ cells of Alexa Fluor 647-conjugated streptavidin (Life Technologies, Carlsbad, CA) at $4^{\circ} \mathrm{C}$ for $30 \mathrm{~min}$.

To assess the percentage of EBV-infected cells [EBV(+) cells] with our previously described method $(5,11)$, we stained EBV-encoded small RNA1 (EBER1) using flow cytometric in situ hybridization developed by Kimura et al. (5) with the peptide nucleic acid probe for tissue sections (Dako, Glostrup, Denmark) and the Alexa Fluor 488 signal amplification kit (Molecular Probe, Eugene, OR).

\section{Measurement of plasma TRAb concentrations}

Plasma TRAb concentrations were quantified using a radio-receptor assay (RRA) according to the manufacturer's instructions (DYNOtest TRAb Human; Yamasa Corporation, Choshi, Japan).

\section{TRAb isotype-enzyme-linked immunosorbent assay}

We examined TRAb-IgG and TRAb-IgM according to a previously described method (6). In brief, all plate wells were coated by $0.1 \mathrm{mg} / \mathrm{L}$ anti-TSHR IgG, incubated at $4{ }^{\circ} \mathrm{C}$ overnight, and then washed. After blocking and washing, we added $4 \mathrm{ng} / \mathrm{mL}$ recombinant human TSHR, shook the plates at room temperature for $30 \mathrm{~min}$, incubated them at $37^{\circ} \mathrm{C}$ for $60 \mathrm{~min}$, and then washed them. We applied $100 \mu \mathrm{L}$ of twice-diluted samples, incubated them at $37^{\circ} \mathrm{C}$ for $60 \mathrm{~min}$, and then washed them. Regarding detection, we used the $3,3^{\prime}, 5,5^{\prime}$-tetramethylbenzidine substrate after an incubation with $100 \mu \mathrm{L}$ of horse radish peroxidaseconjugated goat anti-human IgG-Fc antibody at $37^{\circ} \mathrm{C}$ for $60 \mathrm{~min}$.

\section{Measurement of antibodies against EBV-related antigens}

Plasma levels of the EBV-early antigen (EA) antibody (Epstein-Barr EA enzyme-linked immunosorbent assay [ELISA] IgG; Vercell, Granada, Spain), EBV-viral capsid antigen (VCA)-IgG (anti-Epstein Barr virus [EBV-VCA] IgG human ELISA kit; Abcam, Cambridge, United Kingdom), and EBV-VCA-IgM (anti-Epstein Barr virus [EBVVCA] IgM human ELISA kit; Abcam) were measured using an ELISA kit according to the manufacturer's instructions.

Values were displayed by absorbance (optical density $[O D]=450)$, and cutoff values were calculated as the mean absorbance values of cutoff controls.

\section{Statistical analyses}

We used SPSS Statistics 21 (IBM, Armonk, NY). A MannWhitney $U$ test was adopted for comparisons of TRAb $(+)$ cell percentages between age groups. Kruskal-Wallis test was used to analyze the variations of VCA-IgG and EA.

\section{Results}

\section{Flow cytometry}

We detected lymphocytes with TRAb on their cell surface [TRAb(+) cells] in all cases, except for two (Cases 171 and
172) (Fig. 1A). The percentage of TRAb $(+)$ cells was lower in the 4 months or younger age group than in the other age groups (not significant; $p=0.086$ ).

The numbers of EBV-infected cells $[\mathrm{EBV}(+)$ cells] detected by EBER1 expression were high in 6 of 30 cases $(20.0 \%)$ (Fig. 1B).

$\mathrm{TRAb}(+) \mathrm{EBV}(+)$ double-positive cells were detected in 16 of 30 cases $(53.3 \%)$ (Fig. 1C).

\section{Plasma VCA antibodies}

The cutoff levels (mean absorbance values of cutoff controls) of VCA-IgG and VCA-IgM were 1.61 and 0.99 , respectively (Fig. 2A).

Cases 127, 130, and 172 showed VCA-IgM > VCA-IgG. VCA-IgG showed significant biphasic increases in the 4 months or lower and 5 years or older groups $(p=0.003)$. VCA-IgM was higher than the cutoff level in Cases 182 and 172 .

\section{Plasma EA antibodies}

The cutoff level (mean absorbance values of cutoff controls) of EA antibodies was 0.43 (Fig. 2B).

EA antibodies showed significant biphasic increases in the 4 months or lower and 5-8 months or older groups, particularly in the 5 years or older groups $(p=0.006)$. Among the 16 cases in the 5-8 months to $1-5$ years groups, 7 had levels that were higher than the cutoff, whereas the others also had EA antibodies though at low levels.

\section{Plasma TRAbs}

Low levels of TRAb-RRA were detected in 9 of 30 cases (30.0\%) (Fig. 3A). The level of TRAb-RRA in Case 174 was higher than the clinical cutoff level (1-2 IU/L). Individual levels of TRAb-IgM were higher than those of TRAb-IgG in 21 cases (Fig. 3B).

Cases with high TRAb-IgG or TRAb-IgM levels (100 ng/mL or more), except for Case 127, had EA or VCAIgM levels that were higher than the cutoff $(0.43$ or 0.99 , respectively), whereas Case 127 showed the primary infection pattern (VCA-IgM > VCA-IgG)

\section{Discussion}

We previously proposed the following antibody production pathway induced by EBV lytic reactivation (11-13). EBV lytic reactivation stimulates host $\mathrm{B}$ cells to be plasma cells and to produce antibody (11-13). This pathway does not need to pass through lymphoid tissues or germinal centers; therefore, autoantibody-producing cells that need to be eliminated may complete antibody production through this pathway (12).

\section{EBV primary infection was serologically observed from 5 to 8 months}

During pregnancy, the fetal serum IgG is originated from the maternal circulation across the placenta. The maternally derived IgG levels decrease gradually and are replaced by those of infant origin $(2,9,15)$, which starts production approximately 6 months after birth, although IgM production starts soon after birth $(2,15,17)$. 
3.5

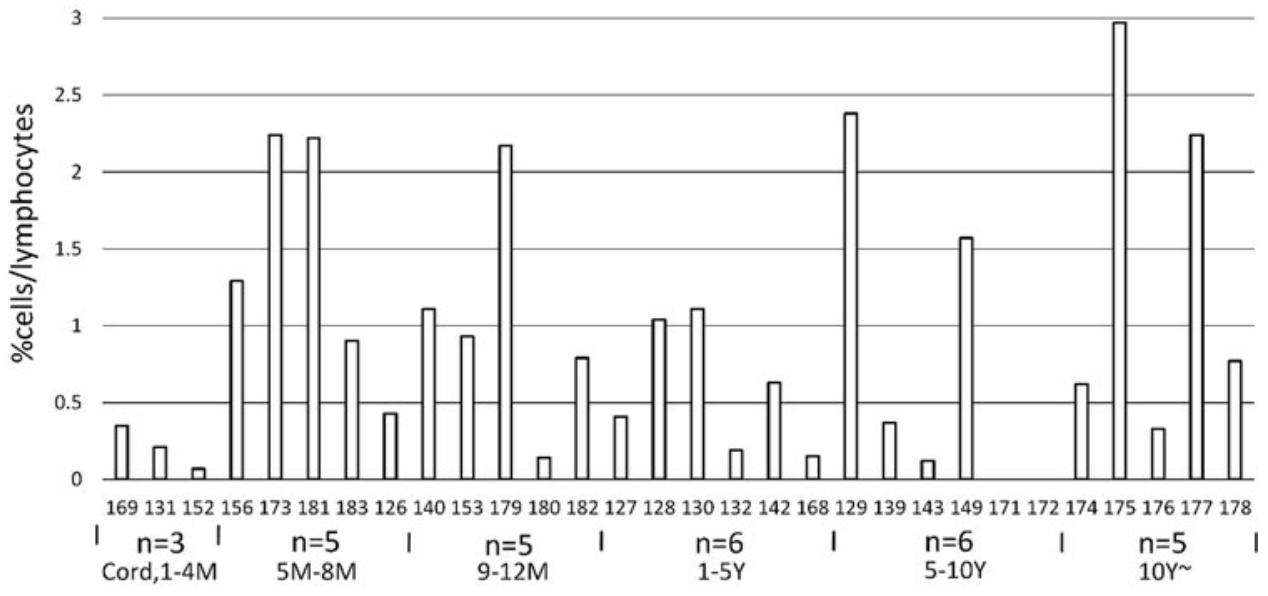

B

EBER1(+)-FCM

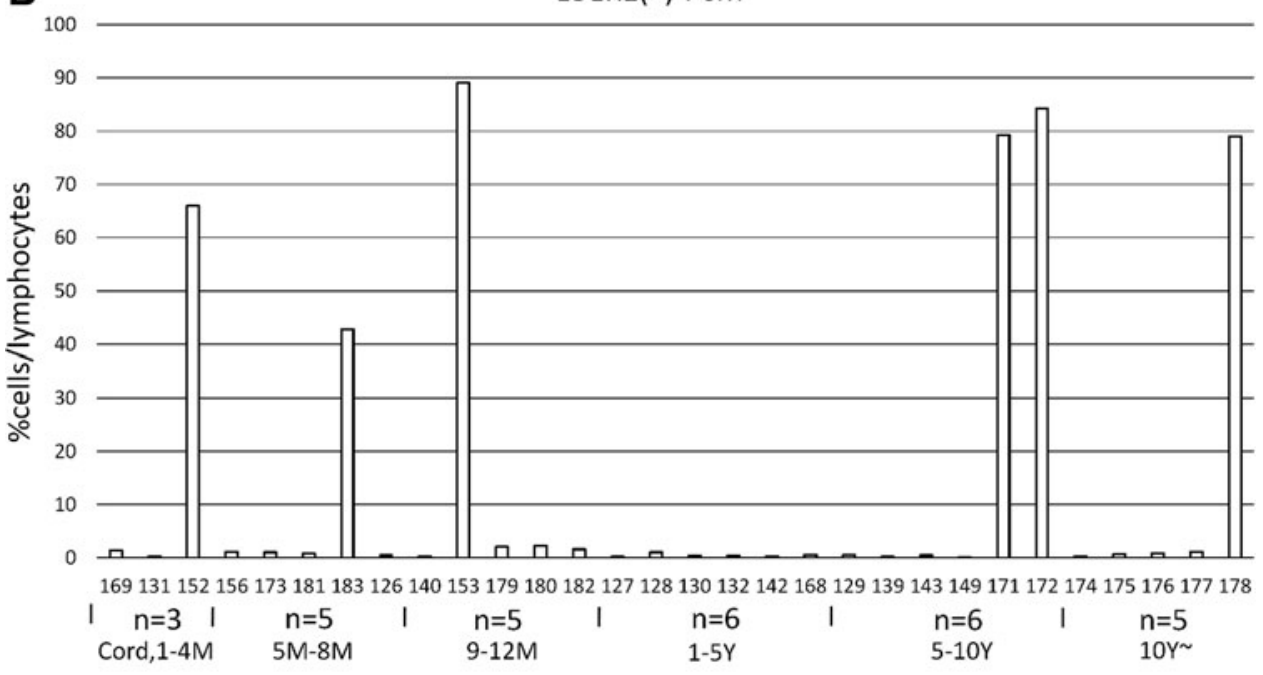

C

$\operatorname{TRAb}(+) \mathrm{EBV}(+)$ double positive cells-FCM

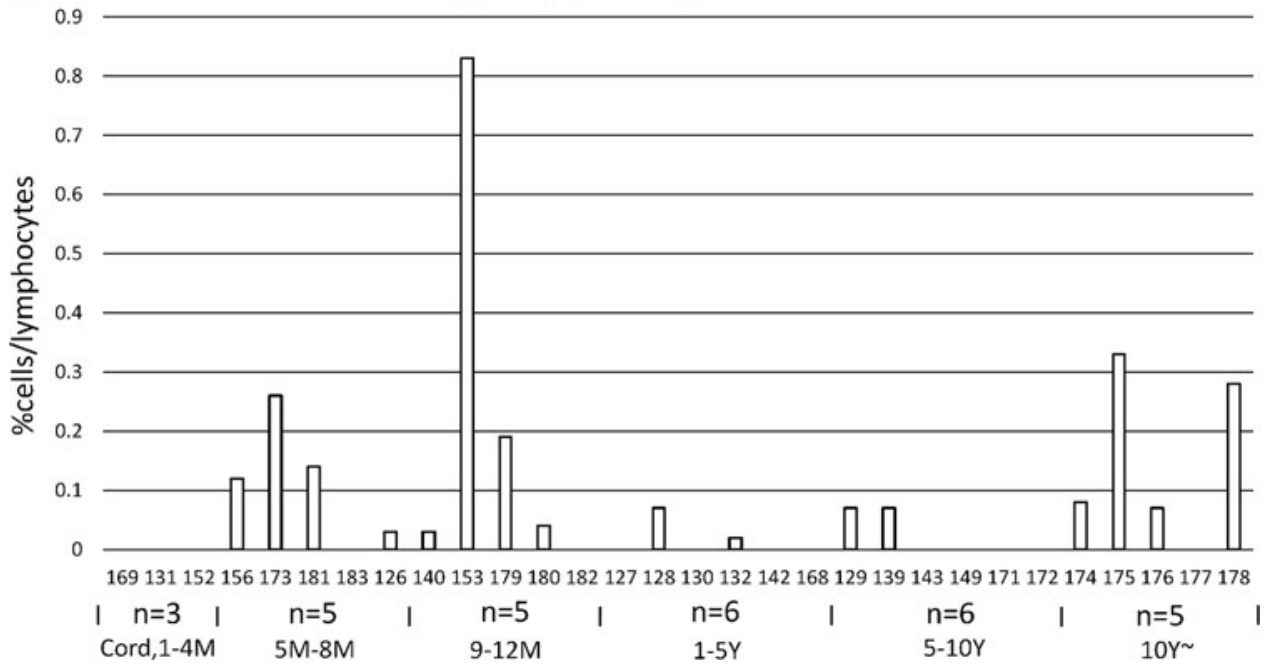

FIG. 1. Analyses of TRAb(+) cells, EBV(+) cells, and TRAb(+) EBV(+) cells by flow cytometry. The results obtained were shown as a percentage of positive cells in the lymphocyte population. $(\mathbf{A})$ TRAb $(+)$ cells was detected in all samples, except for two, and noted an increase in the 5-8 months group compared with the 4 months or younger group $(p=0.086)$. (B) Serologically, most of our subjects were EBV infected; however, only six had obvious EBV $(+)$ cells. In children, EBV $(+)$ cell numbers may be low even after primary infection. (C) TRAb $(+) \operatorname{EBV}(+)$ cell numbers were very small; however, we detected double positive cells in some cases. EBV, Epstein-Barr virus; TRAb, thyrotropin receptor autoantibody. 


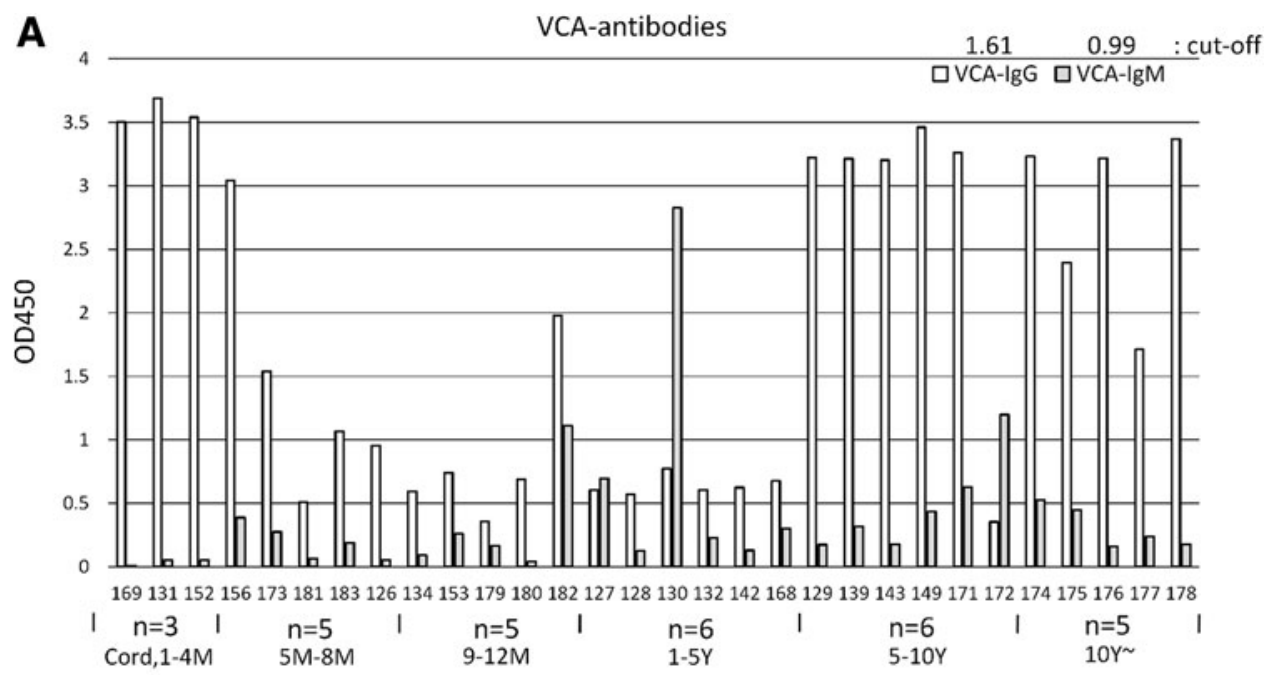

B

EA
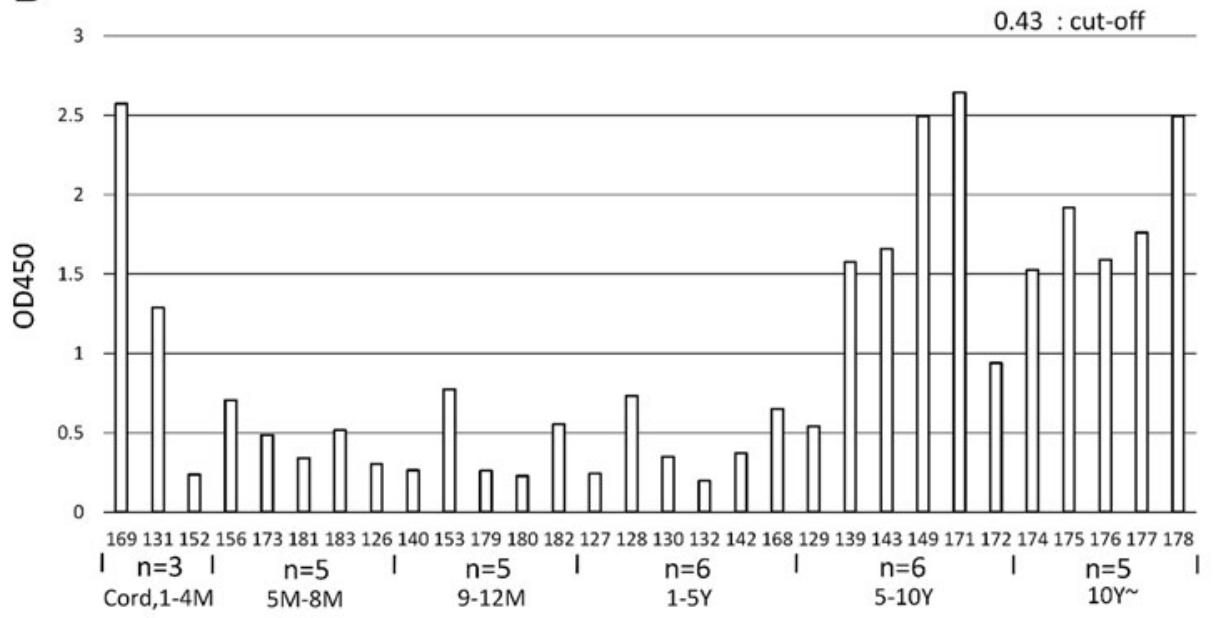

FIG. 2. Identification of the phase of EBV infection by plasma VCA and EA antibodies. High antibody levels in the 4 months or younger group represent maternal antibody levels, whereas those in the 5 years and older group showed postEBV infection and the maturation of antibody production. (A) The cutoff levels (mean absorbance values of cutoff controls) of VCA-IgG and VCA-IgM were 1.61 and 0.99 , respectively. VCA-IgG showed significant biphasic increases in the 4 months or lower and 5 years or older groups $(p=0.003)$. VCA-IgM was higher than the cutoff level in Cases 182 , 130, and 172. Cases 127, 130, and 172 showed VCA-IgM > VCA-IgG. (B) The cutoff level (mean absorbance values of cutoff controls) of EA antibodies was 0.43. EA antibodies showed significant biphasic increases in the 4 months or lower and 5-8 months or older groups, particularly in the 5 years or older groups $(p=0.006)$. Among the 16 cases in the 5-8 months to 1-5 years groups, 7 had levels that were higher than the cutoff, whereas the others also had EA antibodies though at low levels.

The present results revealed that EBV primary infection, detected by the appearance of VCA-IgM, began in the 5-8 months group (Fig. 2A). The children who participated in this study did not exhibit obvious symptoms of IM. Therefore, children aged 5-8 months or older already asymptomatically had EBV primary infection.

During EBV primary infection, most cells become latency type III; however, some are lytically infected $(1,7)$, and the EBV reactivation marker EA increases 3-4 weeks after infection (7). In this study, EA increased to higher than the cutoff level in some cases in the 5-8 months group (Fig. 2B).
Various autoantibodies have been reported to be present in the acute phase of IM, which is the primary infection of EBV $(7,14,16)$. These autoantibodies may be produced through EBV infection and lytic reactivation.

\section{EBV-infected cells may expand through repeated lytic reactivation after primary infection}

The number of EBV-infected cells increases during EBV primary infection or lytic reactivation because of the multiplication of lymphoblastoid cells or new infection with the EBV virions produced (7). 


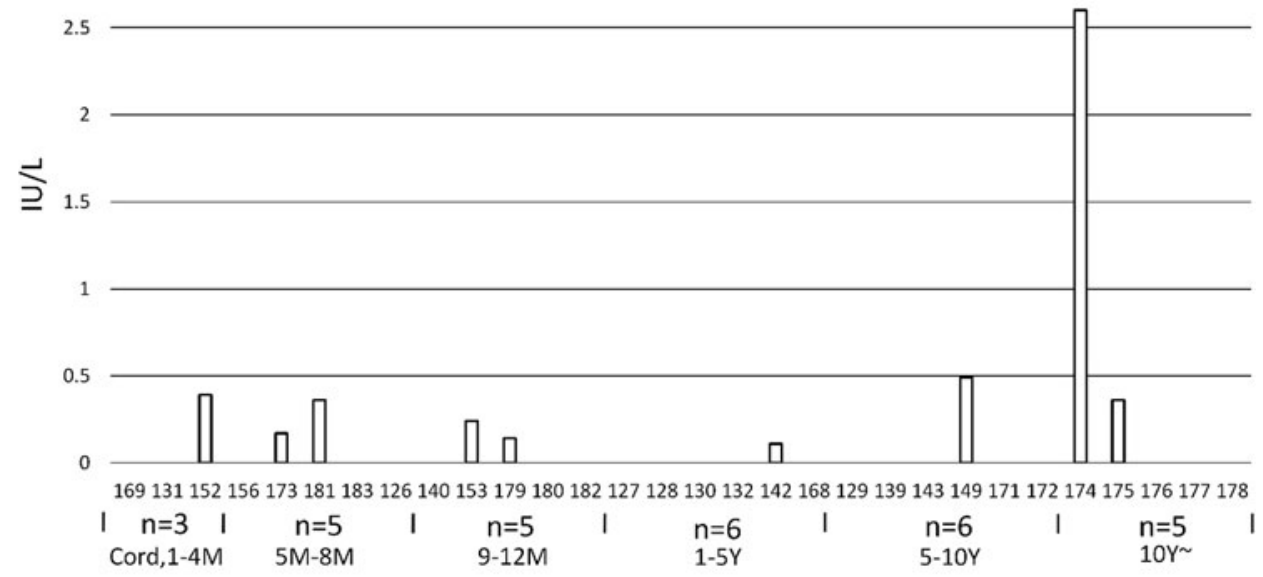

B

TRAb isotype-ELISA
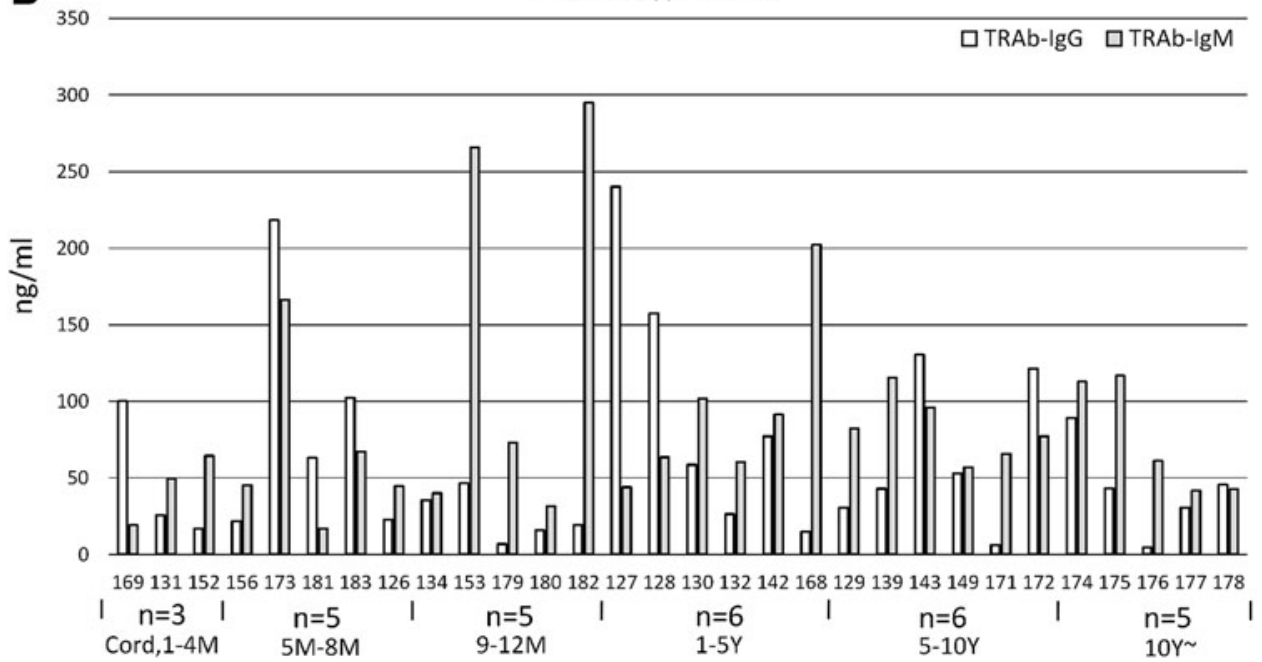

FIG. 3. Plasma TRAb levels measured by two assays. The RRA assesses the inhibition of TSH binding to TSHR by serum TRAbs (A), whereas the ELISA system evaluates the binding of serum TRAbs to recombinant human TSHR (B). (A) RRA showed a small amount of TRAb below the clinical cutoff level (1 IU/L) in several cases. (B) TRAb-isotype ELISA showed that TRAb-IgM levels were higher than TRAb-IgG levels in many cases (21/30 cases). With reference to the EBV antibody (VCA and EA) levels shown in Figure 2, the majority of subjects with high TRAb-IgG or TRAb-IgM levels $(100 \mathrm{ng} / \mathrm{mL}$ or more) had EA or VCA-IgM levels that were higher than the cutoff level (0.43 or 0.99 , respectively). This result suggests that TRAb production occurred with EBV infection or lytic reactivation. ELISA, enzyme-linked immunosorbent assay; RRA, radio-receptor assay; TSHR, thyrotropin receptor.

\section{A Obvious EBER1(+) cell population}

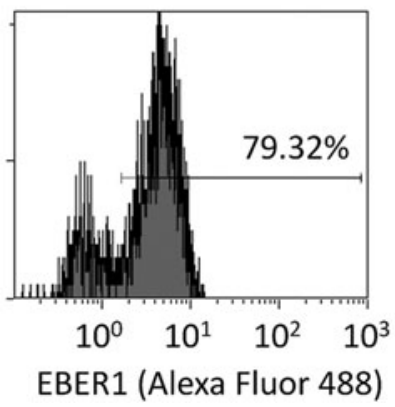

B Small EBER1(+) cell population

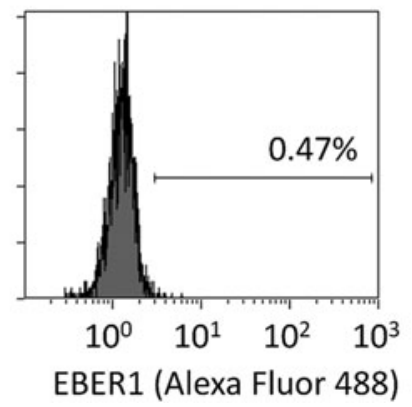

FIG. 4. A representative histogram for EBER1 (Alexa Fluor 488) fluorescence. EBV-infected cells [EBV(+) cells] were detected by EBER1 expression. (A) A histogram of Case 171 with a high EBER1 $(+)$ cell percentage and obvious EBER1(+) cell population (79.32\%). EBER1, EBV-encoded small RNA1. (B) A histogram of Case 126. The population of EBER1 $(+)$ cells was difficult to distinguish from non-specific staining $(0.47 \%)$. 
In our previous study, all healthy adults had an obvious EBER1(+) cell population (11). However, in this study, we detected obvious EBER1(+) cell populations in only 6 of 30 cases $(20.0 \%$ ) (Figs. 1B and 4). Most cases in the 5-8 months or older groups were already serologically infected. Therefore, in contrast to adults, the number of EBV-infected cells may be small in children, even after infection.

We considered the population of $\operatorname{EBV}(+)$ cells to potentially expand through repeated lytic reactivation after primary infection.

\section{Most subjects had TRAb(+) cells that may expand through EBV infection or lytic reactivation}

TRAb-positive lymphocytes [TRAb $(+)$ cells] were detected in all samples, except for two (Cases 171 and 172) (Fig. 1A). This result is consistent with our previous findings showing that most adults have TRAb-producing cells that have evaded selection in the bone marrow (11).

The percentage of TRAb(+) cells was low in the 4 months or younger group, and increased in the 5-8 months or older groups $(p=0.086)$. This period for the expansion of $\mathrm{TRAb}(+)$ cells is the same as the time of EBV primary infection assessed serologically.

All cases, except for Case 127, with high TRAb-IgG or TRAb-IgM levels (100 ng/mL or more) had EA or VCAIgM levels that were higher than the cutoff level $(0.43$ or 0.99, respectively) (Fig. 2), suggesting that TRAb production occurred with EBV infection or lytic reactivation. Even Case 127 with a high level of TRAb-IgG showed the primary infection pattern (VCA-IgM $>$ VCA-IgG).

We propose that the population of $\mathrm{TRAb}(+)$ cells and $\mathrm{TRAb}(+) \mathrm{EBV}(+)$ cells may also expand through repeated lytic reactivation after primary infection. This may partly explain why the onset of Graves' disease often occurs in young adults, but rarely in infancy.

\section{Differences in TRAb levels by RRA and ELISA}

In this study, we measured plasma TRAbs with RRA and TRAb-isotype ELISA, which we used in previous studies (6). However, the results obtained did not necessarily correlate, which may be attributed to differences in the detection system between RRA and ELISA.

RRA assesses the inhibition of TSH binding to TSHR by serum TRAbs (3), whereas ELISA evaluates the binding of serum TRAb to recombinant human TSHR (6). The binding of TRAb-IgM to TSHR may be structurally varied (4), and neutral antibody, which is a type of TRAb, may only be measured by ELISA because they do not occupy TSHR (10).

Maternal TRAb may influence both TRAb-RRA and TRAb-IgG because some healthy mothers have TRAbs that are below the cutoff value.

\section{Conclusion}

In children, TRAb production occurs with EBV primary infection and lytic reactivation, even if they are asymptomatic, which means healthy children occasionally have TRAb.
After primary infection, the population of TRAb $(+)$ cells, $\mathrm{EBV}(+)$ cells, and $\mathrm{TRAb}(+) \mathrm{EBV}(+)$ cells may expand with repeated EBV lytic reactivation.

\section{Acknowledgments}

The authors thank Mr. Takehiko Fukutani (Division of Medical Education, Tottori University) for the assistance. The authors also thank Medical English Service (Kyoto, Japan) for proofreading this article.

\section{Author Disclosure Statement}

No competing financial interests exist.

\section{Funding Information}

This work was supported by JSPS KAKENHI Grant No. 17K08694 (K.N.).

\section{References}

1. Cohen JI. Epstein-Barr virus infection. NEJM 2000;343: 481-492.

2. Collins-Williams C, Toft B, Generoso L, et al. Quantitative immunoglobulin levels (IgG, $\operatorname{IgA}$ and $\operatorname{IgM}$ ) in children, determined by the Hyland Immunoplate technique. Can Med Assoc J 1967;96:1510-1513.

3. Costagliola S, Morgenthaler NG, Hoermann R, et al. Second generation assay for thyrotropin receptor antibodies has superior diagnostic sensitivity for Graves' disease. J Clin Endocrinol Metab 1999;84:90-97.

4. Czajkowsky DM, and Shao Z. The human IgM pentamer is a mushroom-shaped molecule with a flexural bias. Proc Natl Acad Sci U S A 2009;106:14960-14965.

5. Kimura H, Miyake K, Yamauchi Y, et al. Identification of Epstein-Barr virus (EBV)-infected lymphocyte subtypes by flow cytometric in situ hybridization in EBV-associated lymphoproliferative disease. J Infect Dis 2009;200:10731087.

6. Kumata K, Nagata K, Matsushita M, et al. Thyrotropin receptor antibody (TRAb)-IgM levels are markedly higher than TRAb-IgG levels in Graves' disease patients and controls, and TRAb-IgM production is related to EpsteinBarr virus reactivation. Viral Immunol 2016;29:459-463.

7. Longnecker RM, Kieff E, and Cohen J. Epstein-Barr virus. In: Knipe DM, Howley PM, eds. Fields virology, 6th ed. Philadelphia: Lippincott Williams \& Wilkins, 2013:18981959.

8. Mandel SJ, Larsen PR, and Davies TF. Williams textbook of endocrinology, 12th ed. Philadelphia: Saunders, 2011: 362-405.

9. Morell A, Skvaril F, Hitzig WH, et al. IgG subclasses: development of the serum concentrations in normal infants and children. J Pediatr 1972;80:960-964.

10. Morshed SA, and Davies TF. Graves' disease mechanisms: the role of stimulating, blocking, and cleavage region TSH receptor antibodies. Horm Metab Res 2015;47:727-734.

11. Nagata $\mathrm{K}$, Higaki $\mathrm{K}$, Nakayama $\mathrm{Y}$, et al. Presence of Epstein-Barr virus-infected B lymphocytes with thyrotropin receptor antibodies on their surface in Graves' disease patients and in healthy individuals. Autoimmunity 2014;47: 193-200.

12. Nagata K, Kumata K, Nakayama $Y$, et al. Epstein-Barr virus lytic reactivation activates $\mathrm{B}$ cells polyclonally and 
induces activation-induced cytidine deaminase expression: a mechanism underlying autoimmunity and its contribution to Graves' disease. Viral Immunol 2017;30:240-249.

13. Nagata K, Nakayama Y, Higaki K, et al. Reactivation of persistent Epstein-Barr virus (EBV) causes secretion of thyrotropin receptor antibodies (TRAbs) in EBV-infected B lymphocytes with TRAbs on their surface. Autoimmunity 2015;48:328-335.

14. Nagata K, Okuno K, Ochi M, et al. Production of thyrotropin receptor antibodies in acute phase of infectious mononucleosis due to Epstein-Barr virus primary infection: a case report of a child. Springerplus 2015;4:456.

15. Parham P. The immune system, 3rd ed. New York: Garland Science, 2009.

16. Sutton RNP, Emond RTD, Thomas DB, et al. The occurrence of autoantibodies in infectious mononucleosis. Clin Exp Immunol 1974;17:427-436.
17. Vick DJ, Hogge WA, Normansell DE, et al. Determination of normal human fetal immunoglobulin M levels. Clin Diagn Lab Immunol 1995;1:115-117.

Address correspondence to:

Dr. Keiko Nagata

Division of Molecular Pathology

Department of Pathology

Faculty of Medicine

Tottori University

86 Nishi-Cho

Yonago 683-8503

Japan

E-mail: nanamon@theia.ocn.ne.jp 